\title{
Involvement of Reactive Oxygen Species in Hemoglobin Oxidation and Virus Inactivation by 1,9-Dimethylmethylene Blue Phototreatment
}

\author{
Junichi Hirayama, ${ }^{*, a, b}$ Stephen J. Wagner, ${ }^{b}$ Hideki Abe, ${ }^{a}$ Kenji Ikebuchi,${ }^{a}$ and Hisami IkedA ${ }^{a}$ \\ Hokkaido Red Cross Blood Center, ${ }^{a}$ Yamanote 2-2, Nishi-ku, Sapporo 063-0002, Japan and Product Development \\ Department, The Jerome H. Holland Laboratory, American Red Cross Blood Services, ${ }^{b} 15601$ Crabbs Branch Way, \\ Rockville, MD 20855, U.S.A. Received October 10, 2000; accepted January 9, 2001
}

The participation of reactive oxygen species (ROS) in virus inactivation by 1,9-dimethylmethylene blue (DMMB) phototreatment in stroma-free hemoglobin (SFH) was investigated with the use of scavengers, quenchers and enhancer. Virus (R17 bacteriophage) photoinactivation by either activated monomer or dimer DMMB was suppressed by sodium azide (singlet oxygen quencher) and promoted by the substitution of $\mathrm{H}_{2} \mathrm{O}$ for deuterium oxide $\left(\mathrm{D}_{2} \mathrm{O}\right)$, which is known to prolong the lifespan of singlet oxygen. There was no or little effect of mannitol (hydroxyl radical scavenger) and superoxide dismutase (superoxide scavenger) on the photoinactivation.

Similar experiments were conducted to investigate the mechanism of methemoglobin (Met-Hb) formation by the activated monomer of DMMB. There was little effect of the singlet oxygen quencher, histidine, or the enhancer, $\mathrm{D}_{2} \mathrm{O}$, on Met-Hb formation. However, rutin, which inhibits not only singlet oxygen but also other ROS, and mannitol supressed the formation of Met-Hb by activated monomer. The addition of superoxide dismutase (SOD) did not inhibit the formation.

In contrast to the activity of the DMMB monomer, that of the dimer was inhibited by histidine and enhanced by $D_{2} O$. The addition of neither mannitol nor SOD affected Met-Hb formation by activated dimer.

These results collectively suggest that virus photoinactivation by the activated monomer and dimer of DMMB as well as Met-Hb formation by the activated dimer proceed via a singlet oxygen mediated pathway. In contrast, singlet oxygen may play a less important role in Met-Hb formation by the activated monomer.

Key words virus inactivation; dimethylmethylene blue; artificial oxygen carrier; hemoglobin; reactive oxygen species; quencher

The viral safety of blood products has been significantly enhanced as a consequence of improvements in donor screening. However, there are still measurable risks of viral transmission through blood products. ${ }^{1,2)}$ Therefore, processes for the removal and/or inactivation of viruses may represent an additional level of safety for these biological materials.

Hemoglobin derived from human red blood cells is being used to develop a variety of artificial oxygen carriers..$^{3-5}$ Out-dated red cells for transfusion are an important source of human hemoglobin for the development of artificial oxygen carriers. The usual techniques for virus removal or inactivation, respectively, in stroma-free hemoglobin (SFH) are filtration and heat-treatment. ${ }^{6-8)}$ However, a combination of at least two techniques, which have different mechanisms of action, is important for complete elimination. This is the approach that has been adopted for the sterilization of a variety of pooled plasma derivatives and could have implications for a pooled hemoglobin product.

Photosensitizers have been utillized for virus inactivation of blood products. ${ }^{9,10)}$ We have previously reported on virus photoinactivation in SFH by 1,9-dimethylmethylene blue (DMMB). ${ }^{11)}$ Vesicular stomatitis virus (VSV) was inactivated $>6 \log _{10}$ by DMMB without Met-Hb formation using $1 \mu \mathrm{M}$ DMMB and red $(655 \mathrm{~nm})$ LED light. ${ }^{11)}$ These conditions favor activation of monomer DMMB, which has an absorption peak of $c a .650 \mathrm{~nm}$. In other experiments, the requirement of oxygen for virus photoinactivation by DMMB was demonstrated by the failure to achieve inactivation in samples bubbled with nitrogen. ${ }^{12)}$

The absorption spectrum of DMMB in aqueous solutions has two peaks, which represent light absorption from the monomer and dimer forms. ${ }^{12}$ ) Activation of the dimer (max $590 \mathrm{~nm}$ ), in contrast to monomer, resulted in virus photoinac- tivation with photooxidation of hemoglobin to methemoglobin (Met-Hb). ${ }^{11)}$ It was speculated that compared with the dimer, the monomer of DMMB has high affinity to nucleic acids and so inactivates virus without inducing Met- $\mathrm{Hb}$ formation. However, why Met-Hb forms on exposure to activated dimer but not monomer may also be explained by a difference in the reactive oxygen species (ROS) involved in the four events (virus inactivation by monomer DMMB, virus inactivation by dimer DMMB, Met-Hb formation by monomer DMMB and Met-Hb formation by dimer DMMB). Methylene blue (MB) is known to produce not only singlet oxygen but also other ROS. ${ }^{13,14)}$ Therefore, DMMB, which is a derivative of MB, may also produce ROS other than singlet oxygen. In order to clarify which ROS are involved in virus inactivation and Met-Hb formation by activated monomer or dimer DMMB, the extent of the inactivation and formation in the presence or absence of ROS scavengers, quenchers or enhancer was evaluated.

\section{MATERIALS AND METHODS}

Virus Assays Bacteriophage R17 and its host, Escherichia coli $\mathrm{Hfr} \mathrm{C}$, were obtained from David Cook (Cerus Corporation, Concord, CA, U.S.A.). The plaque assay for bacteriophage R17 utilized standard top-agar overlay techniques in petri dishes. ${ }^{12)}$ E. coli $\mathrm{Hfr} \mathrm{C}$ was grown overnight in Trypticase-soy broth cultures (Becton Dickinson, Cockeysville, MD, U.S.A.) at $37^{\circ} \mathrm{C}$ to early stationary phase. We added $220 \mathrm{ml}$ of host bacteria and either $100 \mu \mathrm{l}$ of phototreated or control samples containing bacteriphage to $3 \mathrm{ml}$ of $0.8 \%$ molten top agar $\left(43^{\circ} \mathrm{C}\right)$. The top agar was then overlaid onto Luria broth (Gibco BRL, Paisley, U.K.) plates (1.5\% agar). R17 plaques were evident after overnight incu- 
bation at $37^{\circ} \mathrm{C}$.

Chemicals DMMB was purchased (Polysciences, Warrington, PA, U.S.A.) and purified by medium pressure liquid chromatography. ${ }^{12)}$ Sodium azide was obtained from Merck (Darmstadt, Germany). Mannitol, SOD (bovine erythrocyte), rutin, $\mathrm{D}_{2} \mathrm{O}$ and histidine were purchased from Sigma Chemical Company (St. Louis, MO, U.S.A.).

Phototreatment Samples were illuminated from above and below using an in-house fabricated light box equipped with 100 light-emitting diodes (LED; GL5UR3K1; Sharp, Tokyo, Japan) on each top and bottom panel. All of the irradiation spectrum of the LED (midpeak bandwidth $29 \mathrm{~nm}$; peak $655 \mathrm{~nm}$ ) overlapped with the absorption spectrum of DMMB. The emission spectrum of the LED source did not significantly overlap with the hemoglobin absorption spectrum. Light irradiance was $3.17 \mathrm{~mW} / \mathrm{cm}^{2}$, which was measured by a Kettering radiant power meter (model 4090; Springfield Jarco Instr., Yellow Springs, OH). For $580 \mathrm{~nm}$ irradiation with DMMB, a Polaroid 610 slide projector equipped with a $500 \mathrm{~W}$ tungsten lamp (CZX-DAB, Sylvania, GTE Products Corp., Winchester, KY, U.S.A.) was utilized with a $580 \mathrm{~nm}$ narrow band pass filter (half bandpath, $10 \mathrm{~nm}$ ) to provide fluence rates of $0.49 \mathrm{~mW} / \mathrm{cm}^{2}$. In contrast to the $655 \mathrm{~nm}$ LED source, emission from the tungsten lamp and $580 \mathrm{~nm}$ band pass filter significantly overlapped the hemoglobin absorption spectrum, reducing light penetration through SFH.

One milliliter of the sample was placed into a culture dish (diameter, $35 \mathrm{~mm}$; liquid thickness, $1 \mathrm{~mm}$ ). The sample was incubated for $15 \mathrm{~min}$ in the dark with reciprocal shaking $(70 \mathrm{rpm})$ at room temperature and then irradiated. The irradiation dose was controlled by the irradiation time.

Preparation of SFH The preparation of SFH was prepared according to the method of Nakai et al. ${ }^{15)}$ Briefly, washed red cells obtained from out-dated human red cell concentrates were lysed by the addition of two volumes of $1-6{ }^{\circ} \mathrm{C}$ distilled water and the hemolysate was left at $4{ }^{\circ} \mathrm{C}$ for $10 \mathrm{~min}$. The hemolysate was centrifuged at $36000 \times \boldsymbol{g}$ for $30 \mathrm{~min}$ and the supernatant was first passed through a $0.22 \mu \mathrm{m}$ filter. The filtrate was subsequently filtered using a membrane with $75 \mathrm{~nm}$ pores (BMM, Asahi Chemical Industry Co. Ltd., Tokyo, Japan). The concentration of hemoglobin in final filtrate was $1.08 \mathrm{~mm}$ (4.34 mm heme), which was measured using a kit (Hemoglobin Test) purchased from Wako Pure Chemical Industries, Ltd. (Osaka, Japan).
Characterization of SFH Met-Hb content (Met-Hb[\%]) was measured spectroscopically by the cyanmethemoglobin method using potassium cyanide and potassium ferricyanide. ${ }^{16)}$ SOD activity was measured with an assay kit purchased from Calbiochem-Navabiochem Corporation (San Diego, CA). Catalase activity was measured spectroscopically according to the method of $\mathrm{H}$. Abei. ${ }^{17)}$

\section{RESULTS}

R17 Inactivation by DMMB Phototreatment R17, a nonenveloped single-stranded RNA bacteriophage, was used as a model virus in these experiments. Under conditions that favored the activated monomer ( $655 \mathrm{~nm}$ irradiation), R17 photoinactivation was suppressed $(92.9 \%)$ by $800 \mathrm{~mm}$ of sodium azide (singlet oxygen quencher) ${ }^{18)}$ and promoted $(276 \%)$ by the substitution of $\mathrm{D}_{2} \mathrm{O}$, which is known to prolong the lifespan of singlet oxygen, ${ }^{19)}$ for $\mathrm{H}_{2} \mathrm{O}$ (Fig. 1). The DMMB concentration in the experiment with $\mathrm{D}_{2} \mathrm{O}$ was reduced to $0.04 \mu \mathrm{M}$, because the extent of R17 inactivation $\left(7.27 \log _{10}\right)$ under these conditions was nearly at the detection limit of the assay. There was little (a reduction of $17.9 \%$ ) or no effect of $400 \mathrm{~mm}$ of mannitol (hydroxyl radical scavenger) $^{20)}$ or $570 \mathrm{U} / \mathrm{ml}$ of SOD (superoxide scavenger) ${ }^{21)}$ on R17 photoinactivation (Fig. 1).

DMMB is composed of monomers and dimers in aqueous solution. Dimers predominate as higher concentrations. ${ }^{12}$ In order to inactivate R17 with a $580 \mathrm{~nm}$ light, the DMMB concentration had to be increased, although the dye concentration was below $0.1 \mu \mathrm{M}$ in the experiment in Fig. 1. The photoinactivation was supressed $(88.6 \%)$ by $200 \mathrm{~mm}$ of sodium azide and promoted $(1036 \%)$ by $\mathrm{D}_{2} \mathrm{O}$ under the conditions that favored the activated dimer ( $580 \mathrm{~nm}$ irradiation) (Fig. 2). The effect of $200 \mathrm{~mm}$ of mannitol and $500 \mathrm{U} / \mathrm{ml}$ of SOD on R17 photoinactivation was small (a reduction of $22.7 \%$ and 9.3\%, respectively) (Fig. 2).

These results collectively suggest that virus photoinactivation by either monomer or dimer DMMB proceeds mainly via a singlet oxygen pathway.

Met-Hb Formation on DMMB Phototreatment The increase in Met-Hb content (\% content) was used as a parameter for estimating hemoglobin oxidation. Since Met-Hb did not form under conditions in which VSV was inactivated by $\left.6 \log _{10}, 11\right)$ experiments were conducted under harsher con-
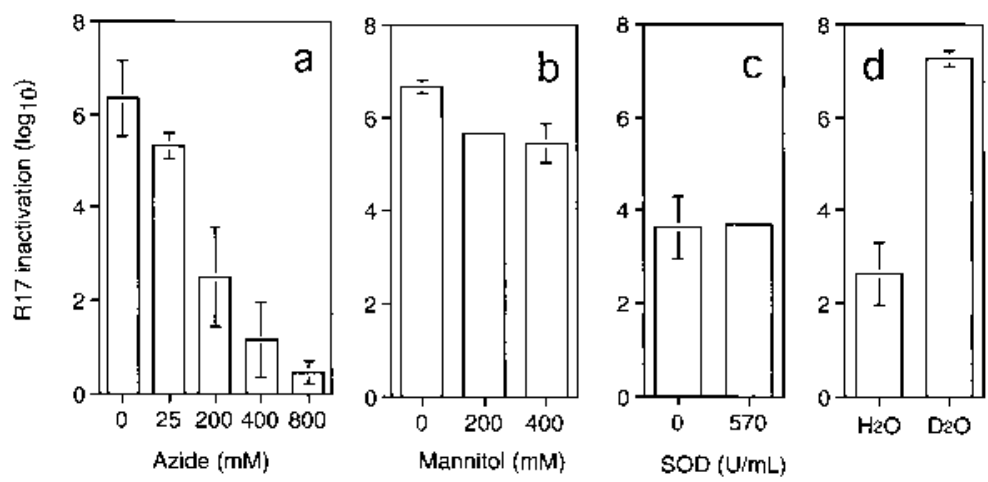

Fig. 1. Effect of Additives on R17 Inactivation by DMMB Phototreatment (655 nm)

R17 inactivation $\left(\log _{10}\right)$ is the difference between R17 inactivation in the presence of DMMB with irradiation and that without irradiation (mean \pm S.D., $n=3-5$ ). a), b) Fluence $1.9 \mathrm{~J} / \mathrm{cm}^{2}(10 \mathrm{~min})$, DMMB $0.1 \mu \mathrm{M}, 100 \mu \mathrm{l}$ Virus $+900 \mu 1$ PBS containing additives. c) Fluence $1.9 \mathrm{~J} / \mathrm{cm}^{2}(10 \mathrm{~min}), \mathrm{DMMB} 0.05 \mu \mathrm{M}, 100 \mu \mathrm{l}$ Virus $+900 \mu \mathrm{l}$ PBS containing additives. d) Fluence $1.9 \mathrm{~J} / \mathrm{cm}^{2}\left(10 \mathrm{~min}\right.$ ), DMMB $0.04 \mu \mathrm{M}, 100 \mu$ Virus $+900 \mu 1$ PBS or $\mathrm{D}_{2} \mathrm{O}$. 

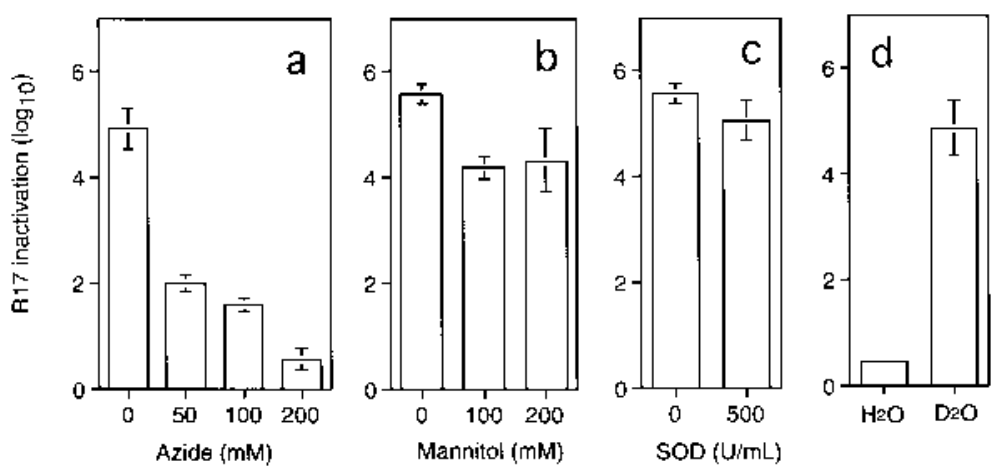

Fig. 2. Effect of Additives on R17 Inactivation by DMMB Phototreatment $(580 \mathrm{~nm})$

R17 inactivation $\left(\log _{10}\right)$ is the difference between R17 inactivation in the presence of DMMB with irradiation and that without irradiation (mean \pm S.D., $\left.n=3,4\right)$. a), b), c) Fluence $0.294 \mathrm{~J} / \mathrm{cm}^{2}$ (10 min), DMMB $1 \mu \mathrm{M}, 100 \mu \mathrm{l}$ Virus $+900 \mu \mathrm{l}$ PBS containing additives. d) Fluence $0.147 \mathrm{~J} / \mathrm{cm}^{2}(5 \mathrm{~min})$, DMMB $0.5 \mu \mathrm{m}, 100 \mu 1$ Virus $+900 \mu 1$ PBS or $\mathrm{D}_{2} \mathrm{O}$.
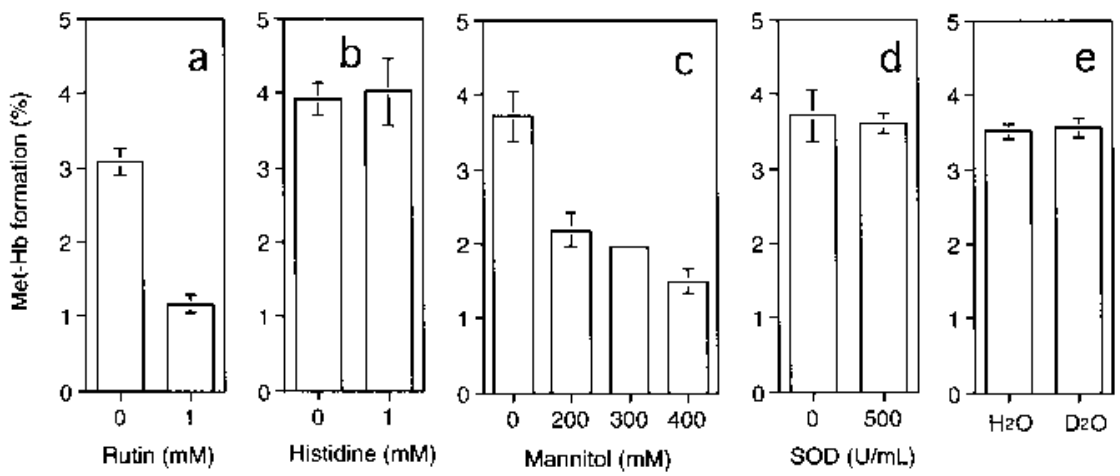

Fig. 3. Effect of Additives on Met-Hb Formation Induced by DMMB Phototreatment ( $655 \mathrm{~nm})$

Met-Hb formation (\%) is the difference between Met-Hb content in the presence of DMMB with irradiation and that without irradiation (mean \pm S.D., $n=2-6)$. a), b) ,c), d) Fluence $1.9 \mathrm{~J} / \mathrm{cm}^{2}(10 \mathrm{~min})$, DMMB $5 \mu \mathrm{M}, 200 \mu \mathrm{l}$ Virus $+800 \mu \mathrm{l}$ PBS containing additives. e) Fluence $1.9 \mathrm{~J} / \mathrm{cm}^{2}(10 \mathrm{~min})$, DMMB $2.5 \mu \mathrm{M}, 100 \mu \mathrm{l}$ Virus $\pm 900 \mu 1 \mathrm{PBS}$ or $\mathrm{D}_{2} \mathrm{O}$.

ditions. In experiments to study the increase of Met-Hb content induced by activated DMMB, sodium azide was not utilized because the chemical itself oxidized the $\mathrm{Fe}^{2+}$ of heme, resulting in Met-Hb formation (data not shown). Rutin and histidine concentrations $>1 \mathrm{~mm}$ had the same effect (data not shown).

Met-Hb formation by activated monomer DMMB was suppressed (62\%) by the addition of $1 \mathrm{~mm}$ rutin, which inhibited not only singlet oxygen but also other ROS (Fig. 3). ${ }^{22-24)}$ The addition of $400 \mathrm{~mm}$ mannitol also supressed (59.6\%) Met-Hb formation (Fig. 3). However, the singlet oxygen quencher, hisitidine $(1 \mathrm{~mm})$, which has a high quenching rate constant for singlet oxygen $\left(4.6 \times 10^{7} / \mathrm{M} / \mathrm{s}\right){ }^{25)}$ did not supress the formation, nor did the substitution of $\mathrm{D}_{2} \mathrm{O}$ for $\mathrm{H}_{2} \mathrm{O}$ enhance it (Fig. 3), although the formation induced by the activated dimer of DMMB was supressed by $1 \mathrm{~mm}$ histidine and enhanced by substitution of $\mathrm{D}_{2} \mathrm{O}$ (Fig. 4). The addition of $500 \mathrm{U} / \mathrm{mL}$ SOD did not affect the formation of Met-Hb (Fig. 3). These results collectively suggest that ROS other than singlet oxygen participates in Met-Hb formation by activated monomer DMMB.

The formation induced by the activated dimer was supressed $(40.9 \%)$ by the addition of $1 \mathrm{~mm}$ histidine and promoted (163\%) by the substitution of $\mathrm{D}_{2} \mathrm{O}$ for $\mathrm{H}_{2} \mathrm{O}$ (Fig. 4). Mannitol (400 mM) and SOD (500 U/ml) did not supress the formation (Fig. 4). These results suggest that mainly singlet oxygen participates in Met-Hb formation by activated dimer DMMB.

SOD and CAT Activity in SFH after DMMB Pho-
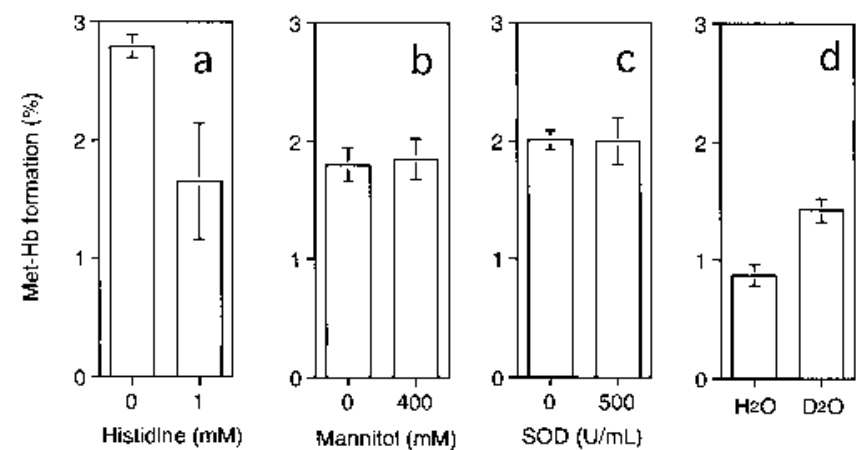

Fig. 4. Effect of Additives on Met-Hb Formation Induced by DMMB Phototreatment $(580 \mathrm{~nm})$

Met-Hb formation (\%) is the difference between Met-Hb content in the presence of DMMB with irradiation and that without irradiation (mean \pm S.D., $n=3-6$ ). a), b) ,c) Fluence $1.18 \mathrm{~J} / \mathrm{cm}^{2}$ (40 min), DMMB $30 \mu \mathrm{M}, 200 \mu$ l Virus $+800 \mu$ l PBS containing additives. d) Fluence $1.18 \mathrm{~J} / \mathrm{cm}^{2}$ (40 min), DMMB $15 \mu \mathrm{M}, 100 \mu \mathrm{l}$ Virus $+900 \mu \mathrm{l}$ PBS or $\mathrm{D}_{2} \mathrm{O}$.

totreatment SOD and CAT activity in SFH were measured before and after DMMB phototreatment (details are described in Materials and Methods and the legend of Figs. 3 and 4). SOD activities in SFH before, and after $660 \mathrm{~nm}$ or $580 \mathrm{~nm}$ irradiation were $6.25 \pm 0.15 \mathrm{U} / \mathrm{ml}, 5.78 \pm 0.41 \mathrm{U} / \mathrm{ml}$ and $6.11 \pm 0.19 \mathrm{U} / \mathrm{ml}$, respectively. CAT activities in SFH before, and after $660 \mathrm{~nm}$ or $580 \mathrm{~nm}$ irradiation were $177.3 \pm$ $4.5 \mathrm{U} / \mathrm{mg}, 166.3 \pm 2.7 \mathrm{U} / \mathrm{mg}$ and $165.5 \pm 2.5 \mathrm{U} / \mathrm{mg}$, respectively (mean \pm S.D., $n=4$ ). These results indicate that the SOD and CAT activity in SFH remained after DMMB pho- 
totreatment.

\section{DISCUSSION}

The effect of additives on virus photoinactivation and Met$\mathrm{Hb}$ formation by DMMB in SFH was studied. The utilization of scavengers, quenchers or enhancers is the method most often used to investigate the role of ROS in photosensitization reactions. ${ }^{26}$ The azide concentration required to suppress virus inactivation is relatively high (Figs. 1 and 2). Singlet oxygen may be generated so close to nucleic acid that it reacts with nucleic acid before it reacts with azide. The requirement of a high concentration of azide to inhibit the photosensitizing reaction involving singlet oxygen was reported in another study. ${ }^{27)}$

The addition of SOD had little effect on the formation of Met-Hb (Figs. 3 and 4). This indicates that superoxide is little involved in the formation or superoxide is scavenged by preexisting SOD, because the SOD activity in SFH was shown to be retained after DMMB phototreatment in this study.

Spectroscopic analysis and equilibrium dialysis experiments suggested that the DMMB monomer has a greater affinity to nucleic acid than the dimer as evidenced by conversion of the dimer to the monomer form on addition of nucleic acid. ${ }^{12)}$ There is no data about the conversion of dimer to monomer on addition of virus particles instead of naked nucleic acid. Although a singlet oxygen yield of DMMB is $50 \%$ greater than that of $\mathrm{MB}$, virus inactivation by $\mathrm{DMMB}$ is roughly 10 times greater than that by $\mathrm{MB} .{ }^{12)}$ Activation of DMMB monomer resulted in virus inactivation without Met$\mathrm{Hb}$ formation. ${ }^{11)}$ Compared with the monomer, larger dimer may sterically prevent binding of the dyes to major or minor grooves of nucleic acids in virus particle. These collectively suggest that the monomer has high affinity to not only naked nucleic acid but also nucleic acid in virus particles.

We speculated that Met-Hb formation by activated monomer proceeds via ROS other than singlet oxygen. Rutin inhibits several ROS (singlet oxygen, hydroxyl radical, hydrogen peroxide etc. $)^{22-24)}$ and mannitol scavenges hydroxyl radicals. Therefore, the hydroxyl radical is a candidate. There are reports that $\mathrm{MB}$ photosensitization proceeds via a hydroxyl radical-mediated pathway. ${ }^{13,14)}$ DMMB may also produce hydroxyl radicals. Ferryl hemoglobin may be also another candidate. The SOD activity in SFH is not lost after DMMB phototreatment. If superoxide was produced by DMMB phototreatment, it would be converted to hydrogen peroxide by SOD in phototreated SFH. We also showed in this study that the CAT activity in SFH was retained after DMMB phototreatment. CAT would convert hydrogen peroxide to water and oxygen. Therefore, the possibility that hydrogen peroxide is involved in the formation of Met- $\mathrm{Hb}$ induced by activated DMMB is low. However, if CAT activity is not enough to quench hydrogen peroxide completely, hydrogen peroxide may induce the formation of Met-Hb which may be converted to hydroxyl radical by $\mathrm{Fe}^{2+}$ of hemoglobin via the Fenton reaction. Here we showed that the activated DMMB monomer can produce singlet oxygen but the singlet oxygen did not play an important role in Met-Hb formation.
The lifespan of singlet oxygen is so short that it can not diffuse far in aqueous solution. ${ }^{19)}$ Therefore, if monomer DMMB has not only stronger affinity to nucleic acid in virus particle but also weaker affinity to hemoglobin, ROS having long lifespan may be involved in Met-Hb formation. Further investigation is needed.

Acknowledgements The author would like to thank Dr. Leonard I. Friedman for supporting this project and Dr. Alfred J. Katz for reviewing this manuscript. This work was financially supported by Japanese Health Science Foundation and Grants-in Aid for Scientific Research from the Japanese Ministry of Education, Science, Sports and Culture.

\section{REFERENCES}

1) Dodd R. Y., Int. Ophthalmol. Clin., 29, 83-88 (1989).

2) Schreiber G. B., Busch M. P., Kleinman S. H., Korelitz J. J., N. Engl. J. Med., 334, 1685-1689 (1996).

3) Tsuchida E., “Artificial Red Cells,” ed. by Tsuchida E., John Willey \& Sons Ltd., 1995, pp. 1-20.

4) Sekiguchi S., Nakai K., “Artificial Red Cells,” ed. by Tsuchida E., pp. 259-275. John Willey \& Sons Ltd., 1995, pp. 259-275.

5) Chang T. M. S., Art. Cells, Blood Subs., and Immob. Biotech., 25, $1-$ 24 (1997).

6) Iwashita W., "Artificial Red Cells," ed. by Tsuchida E., John Willey \& Sons Ltd., 1995, pp. 151-176

7) Bechtel M. K., Bagdasarian A., Olson W. P., Estep T. N., "Blood Substitutes,” ed. by Chang T. M. S., Geyer R. P., 1989, pp. 123-128.

8) Estep T. N., Bechtel M. K., Miller T. J., Bagdasarian A., "Blood substitutes," ed. by Chang T. M. S., Geyer R. P., 1989, pp. 129-134.

9) Horowitz B., Ben-Hur E., Photochem. Photobiol., 62, 383-388 (1995).

10) Wagner S. J., Skripchenko A., Robinette D., Mallory D. A., Hirayama J., Cincotta L., Foley J., Dev. Biol. Stand., 102, 125-129 (2000).

11) Hirayama J., Wagner S. J., Gomez C., Macdonald V. W., Abe H., Ikeda H., Ikebuchi K., Sekiguchi S., Photochem. Photobiol., 71, 90-93 (2000).

12) Wagner S. J., Skripchenko A., Robinette D., Foley J. W., Cincotta L., Photochem. Photobiol., 67, 343-349 (1998).

13) Kamat J. P., Devasagayam T. P., Chem. Biol. Interact., 99, 1-16 (1996).

14) Buettner G. R., Doherty T. P., Bannister T. D., Radiat. Environ. Biophys., 23, 235-243 (1984).

15) Nakai K., Matsuda N., Ohta T., Amano M., Takahashi T. A., Sakuma I., Kitabatake A., Ito S., Nakazato Y., Sekiguchi S., Artif. Organs., 18, 198-205 (1994).

16) van Kampen E. J., Zijlstra W. G., Adv. Clin. Chem., 8, 141-187 (1965).

17) Abei H., "Methods in Enzymology," Vol. 105, ed. by Packer L., Academic Press, 1984, 121

18) Hasty N., Markel P. B., Radlick P., Kearns D. R., Tetrahedron Lett., 1, 49-52 (1972).

19) Rodgers M. A. J., J. Am. Chem. Soc., 105, 6201-6205 (1983).

20) Peak M. J., Peak J. G., Photochem. Photobiol., 51, 649-652 (1990).

21) Petkau A., Chuaqui C. A., Radiat. Phys. Chem., 24, 307-319 (1984).

22) Chin S., Williams B., Gottlieb P., Margolis-Nunno H., Ben-Hur E., Hamman J., Jin R., Dubovi E., Horowitz B., Blood, 86, 4331-4336 (1995)

23) Marx G., Mou X., Freed R., Ben-Hur E., Yang C., Horowitz B., Photochem. Photobiol., 63, 541-546 (1996).

24) Aherne S. A., O’Brien N. M., Nutr. Cancer, 34, 160-166 (1999).

25) Michaeli A., Feilelson J., Photochem. Photobiol., 59, 284-289 (1994).

26) Rywkin S., Lenny L., Goldstein J., Geacintov N. E., Margolis-Nunno H., Photochem. Photobiol., 56, $463-469$ (1992).

27) Spikes J. D., Bommer J. C., Photochem. Photobiol., 58, 346-350 (1993). 